\title{
Interface Mixing in Fe/Si Multilayers Observed by the In Situ Conductance Measurements
}

\author{
P. Chomiuk*, M. BŁaszyk, B. Szymański and T. Luciński \\ Institute of Molecular Physics, Polish Academy of Sciences \\ M. Smoluchowskiego 17, 60-179 Poznań, Poland
}

\begin{abstract}
In this contribution the in situ conductance vs. deposition time dependences of $\mathrm{Fe} / \mathrm{Si}$ multilayers are analysed. The plot of resistance multiplied by the square of the thickness as a function of iron thickness shows that during the iron deposition initially amorphous-like $\mathrm{Fe}-\mathrm{Si}$ mixture is formed, next the mixture crystallises, and finally bcc-Fe phase appears. The interface mixing is also manifested by the reduction of the total multilayer thickness measured by small angle X-ray diffraction.
\end{abstract}

PACS numbers: 73.40.Sx, 73.50.-h

\section{Introduction}

The Fe/Si multilayers (Mls) exhibit a strong antiferromagnetic (AF) coupling $[1,2]$. A lot of papers have been devoted to this system in order to clarify the origin of the interlayer interaction (see [1-3] and references therein). The AF interlayer coupling is affected by the interdiffusion of $\mathrm{Fe}$ and $\mathrm{Si}$, leading to the formation of various $\mathrm{Fe}-\mathrm{Si}$ mixtures. Therefore, in order to observe both the intermixing process and growth of individual layers, in situ conductance measurements during the multilayer deposition were performed. In our previous paper [3] we reported conductance vs. deposition time dependences of $\mathrm{Fe} / \mathrm{Si}$ and $\mathrm{Fe} / \mathrm{Ge} \mathrm{Mls}$. A model describing the growth of the individual layers was proposed. Within this model, during Fe deposition, initial slow increase in conductance is due to intermixing of iron with underlying silicon. Subsequently an abrupt change of conductance is noticed, which suggests the modification of the iron growth mode or a structural transition. This transition takes place at about $1.7-2.3 \mathrm{~nm}$ and depends on the layer number. Further deposition of iron leads to growth of the bcc-Fe phase. During Si deposition, at the early stage, due to interdiffusion of $\mathrm{Si}$ into $\mathrm{Fe}$, an $\mathrm{Fe}-\mathrm{Si}$ mixture is formed, thus a decrease in conductance is observed. Subsequent $\mathrm{Si}$ deposition on the $\mathrm{Fe}-\mathrm{Si}$ mixture leads to the growth of nonconductive silicon, hence $G(t)$ plateau appears. Such a plateau was observed only in $\mathrm{Fe} / \mathrm{Si}$ Mls which exhibit no $\mathrm{AF}$ coupling, i.e., for $d_{\mathrm{Si}}>1.3 \mathrm{~nm}$.

In this contribution we focus on the analysis of the evolution of the iron growth mode and its structural changes.

\section{Experimental}

The $\mathrm{Fe} / \mathrm{Si}$ multilayers have been deposited at room temperature by magnetron sputtering onto oxidised

\footnotetext{
* corresponding author; e-mail: chomiuk@ifmpan.poznan.pl
}

Si substrates. The process conditions and experimental details have been described in [3]. Several multilayers with various thicknesses of individual sublayers were expected to correspond to specific cases: the $[\mathrm{Fe}(3 \mathrm{~nm}) / \mathrm{Si}(1.3 \mathrm{~nm})]_{15}+\mathrm{Fe}(3 \mathrm{~nm})$ and $[\mathrm{Fe}(3 \mathrm{~nm}) / \mathrm{Si}(2.5 \mathrm{~nm})]_{15}+\mathrm{Fe}(3 \mathrm{~nm})$ Mls correspond to the maximum and the absence of the AF coupling [1], respectively, and the $[\mathrm{Fe}(0.5 \mathrm{~nm}) / \mathrm{Si}(1.3 \mathrm{~nm})]_{15}$ $+\mathrm{Fe}(0.5 \mathrm{~nm}) \mathrm{Ml}$ corresponds to the amount of iron, which forms magnetically inactive layer [2]. The small angle X-ray diffraction (SAXRD) profile was recorded in standard $\theta-2 \theta$ geometry with $\mathrm{Cu} K_{\alpha}$ radiation.

\section{Results and discussion}

Figure 1 displays the in situ conductance (1a) and the resistance multiplied by the square of the thickness for 5th, 10th, and 15th iron layer (1b). The curves from Fig. 1a expressed as $R d_{\mathrm{Fe}}^{2}$ (Fig. 1b) are very similar to those presented by Dufour et al. [4]. They consider a resistance-square dependence, which is in fact the resistance multiplied by a constant factor of the sample area. The slope of the dependence describes the dynamical resistivity and provides information about crystallisation process. In the $R d_{\mathrm{Fe}}^{2}$ vs. $d_{\mathrm{Fe}}$ plot three stages can be distinguished. Large resistivity of the first stage (I) is typical of the amorphous materials. Iron and silicon react easily and form amorphous alloys [5]. The drop of the dynamical resistivity in the second part (II) corresponds to the crystallisation of the amorphous $\mathrm{Fe}-\mathrm{Si}$ mixture in the layer, and the less steep slope in the third stage (III) reflects the growth of crystalline iron. The presence of the bcc-Fe phase has been confirmed by the X-ray diffraction study and the Mössbauer spectroscopy [6].

Since the every next Fe layer is deposited onto the multilayer stack with increasing total thickness, the measured resistance is influenced by the whole multilayer and thus the resistance drop in the curves of the latter iron layers is less pronounced due to the shunting 


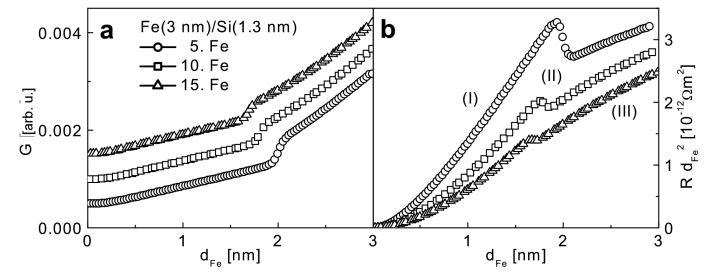

Fig. 1. In situ conductance (a) and resistance multiplied by square Fe thickness (b) as a function of iron thickness for 5th, 10th and 15th Fe sublayer of $\mathrm{Fe}(3 \mathrm{~nm}) / \mathrm{Si}(1.3 \mathrm{~nm})$ superlattice.

effect. The in situ conductance vs. deposition time of $\mathrm{Fe}(0.5 \mathrm{~nm}) / \mathrm{Si}(1.3) \mathrm{Ml}$ is shown in Fig. 2. In this case the sharp increase in the $G(t)$ is not observed since the deposited iron layer is much thinner than the observed critical thickness required for the growth mode transition.

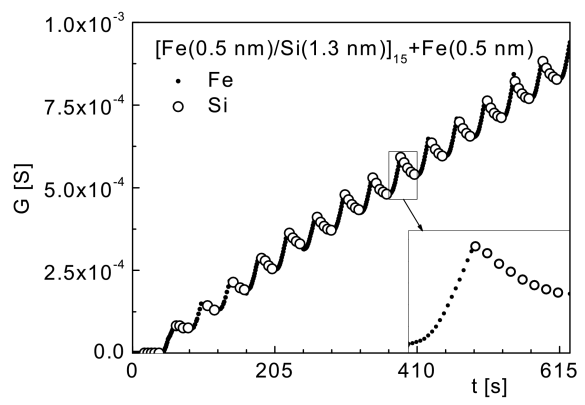

Fig. 2. In situ conductance vs. deposition time of $\mathrm{Fe}(0.5 \mathrm{~nm}) / \mathrm{Si}(1.3 \mathrm{~nm}) \mathrm{Ml}$.

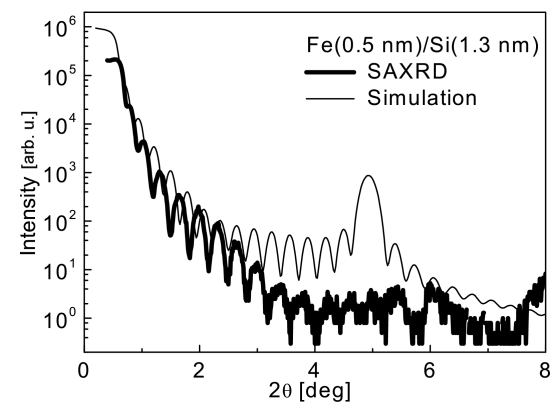

Fig. 3. SAXRD profile of the $\mathrm{Fe}(0.5 \mathrm{~nm}) / \mathrm{Si}(1.3 \mathrm{~nm})$ $\mathrm{Ml}$ and the simulation with assumed no intermixing.

The diffraction profile obtained for the $\mathrm{Fe}(0.5 \mathrm{~nm}) /$ $\mathrm{Si}(1.3 \mathrm{~nm}) \mathrm{Ml}$ and a simulated one, with assumed no intermixing at interfaces, are shown in Fig. 3. A notice- able peak in the simulation plot at about $5^{\circ}$ originates from the assumed multilayered structure. In the case of $\mathrm{Fe}(0.5 \mathrm{~nm}) / \mathrm{Si}(1.3 \mathrm{~nm}) \mathrm{Ml}$ no Bragg-like maximum related to superlattice in the SAXRD profile was found. It suggests that no pronounced multilayered structure is present in the sample, i.e. the interface mixing may lead to the blur interfaces and modulation period fluctuations. Due to weak chemical contrast Bragg-like peak does not appear in the SAXRD profile. The total thickness of the sample determined from the Kiessig fringes in the SAXRD profile $(25.5 \mathrm{~nm})$ is $2 \mathrm{~nm}$ shorter than the nominal thickness $27.5 \mathrm{~nm}$, which is also the result of intermixing.

\section{Conclusions}

In the $\mathrm{Fe} / \mathrm{Si}$ superlattices with $3 \mathrm{~nm}$ thick iron layer a growth mode transition occurs. The analysis of $R d_{\mathrm{Fe}}^{2}$ vs. iron thickness dependence shows that this transition is most probably due to crystallisation of the amorphous-like Fe-Si mixture. With increasing layer number the drop of the dynamical resistivity is less pronounced due to the shunting effect. For thin iron layer $(0.5 \mathrm{~nm})$ no structural transition is noticed. The SAXRD pattern shows reduction of the total thickness and no audible periodic structure of the multilayer, which is the effect of interface mixing leading to formation of amorphous-like structure.

\section{Acknowledgments}

This work was supported from the science resources as a joint research within scientific network "New materials and sensors for optoelectronics, informatics, energetic and medicine". We are grateful to J. Aleksiejew and M. Schmidt for sample preparation.

\section{References}

[1] T. Luciński, P. Wandziuk, F. Stobiecki, B. Andrzejewski, M. Kopcewicz, A. Hütten, G. Reiss, W. Szuszkiewicz, J. Magn. Magn. Mater. 282, 248 (2004).

[2] T. Luciński, P. Wandziuk, B. Szymański, J. Baszyński, F. Stobiecki, J. Zweck, Phys. Status Solidi C 3, 93 (2006).

[3] P. Chomiuk, M. Wróblewski, M. Błaszyk, T. Luciński, B. Susła, Acta Phys. Pol. A 113, 657 (2008).

[4] C. Dufour, A. Bruson, G. Marchal, B. George, Ph. Mangin, J. Magn. Magn. Mater. 93, 545 (1991).

[5] Ph. Mangin, G. Marchal, B. Rodmacq, Chr. Janot, Philos. Mag. 36, 643 (1977).

[6] T. Luciński, M. Kopcewicz, A. Hütten, H. Brückl, S. Heitmann, T. Hempel, G. Reiss, J. Appl. Phys. 93, 6501 (2006). 